\title{
Listening to the grass roots: Bottom-up approaches to lifelong learning
}

\author{
Stephen Roche ${ }^{1}$
}

Published online: 4 April 2017

(C) Springer Science+Business Media Dordrecht and UNESCO Institute for Lifelong Learning 2017

For close to a century, scholars of international and comparative education have sought to identify best practice and considered ways of transplanting successful approaches from one context to another. Yet, despite countless global education initiatives, international studies and reform initiatives, massive disparities persist within and between countries - in terms of access, opportunity and quality. There are, of course, some notable, even dramatic, indicators of success. These include primary school enrolment in most of Africa, literacy in Latin America and access to tertiary education in much of Asia, Europe and North America. However, if public education is intended to promote greater social equity and equality, the widening global wealth gap (albeit in the context of overall growth in prosperity) seems a glaring indicator of failure (Lakner and Milanovic 2013; Hickel 2016). There is more public spending on education today than ever before (though spending as a proportion of GDP has remained static at around 5 per cent in most of the wealthier countries since the 1960s and has even dipped slightly in recent years) (Tanzi and Schuknecht 2000), yet social inequality not only persists, but has worsened. Why is this so? As with every social effect, there are multiple possible causes. But, returning to the metaphor of transplantation, I believe a significant part of the answer lies in a failure to adequately prepare the ground. There is also the issue of motivation; of imposition versus borrowing. People instinctively resist whatever they perceive to be imposed from above or abroad. This is especially true in countries with a history of colonial rule. The astonishing adoption rate of mobile phone technology in the developing world offers a salient lesson for educationists; the seed fell on ready ground, and germinated with little inducement.

What does it mean to develop a bottom-up approach to education and lifelong learning? Adapting a popular metaphor, I would say it means putting our ears to the

Stephen Roche

s.roche@unesco.org

1 UNESCO Institute for Lifelong Learning, Hamburg, Germany 
ground and listening to the grass roots. It means understanding - through consultation, observation and analysis - the needs, motivations and opinions of grass-roots stakeholders such as learners, teachers and the parents of school-going children. I am not suggesting that the ideas and opinions of researchers and policymakers should be discounted; rather, "parity of esteem" is needed between those who develop education policy and those who implement it. If the two fail to synchronise, the policy initiative - whether individual intervention or large-scale reform - is unlikely to take root and bear fruit. This is a point so obvious it hardly bears mentioning. Yet the field of comparative education is strewn with policy initiatives that failed, or at least failed to meet expectations. Of course, other factors, such as funding or political change, also influence success or failure of education reform, but research has demonstrated the vital centrality of local acceptance and sense of ownership (Samoff and Sebatane 2013). All of the articles in this issue are about working with stakeholders to develop more effective, responsive and inspiring initiatives, thereby helping to build that much-vaunted yet elusive entity, the learning society.

Following the terrorist attacks of 11 September 2001, there was much talk of understanding the hatred that inspired these acts, and of "winning over hearts and minds" in the Muslim world; in other words, promoting peace and tolerance (albeit alongside war and "regime change"). Judging by the spread and growth of radical Islamism in the decade and a half since, that attempt has been scarcely more successful than the military campaigns. In retrospect, it seems likely that it failed for many of the same reasons: because of a belief that solutions can be imposed from above, and that one "size" of intervention fits all contexts. The authors of our first article argue that a flaw of the approach to peace education pursued by Western donors, local and international NGOs, and the governments of many Muslimmajority countries was its reliance on a secularist model and a top-down approach. This approach was viewed with suspicion or even as a threat by many traditional communities. Local religious Qur'anic schools, by contrast, enjoy a high degree of trust and confidence in many Muslim-majority countries, as they rest on a longstanding tradition. That trust, which fosters a sense of legitimacy, is a crucial and indispensable factor in peace education.

In an article entitled "Building peace education in the Islamic educational context", authors Mohammed Abu-Nimer and Ilham Nasser describe and evaluate a pilot project conducted by an NGO, the Salam Institute, to introduce a peace education curriculum into Qur'anic schools in Zinder province, Niger. The recent emergence in the Sahel region of extremist groups such as Boko Haram makes the locus of this study particularly pertinent. The project worked within the framework of existing curricula in Qur'anic schools and contained an element of action research and teacher training in the development and piloting of a training manual. The authors found that school leaders and teachers were much more receptive to peace education when this was based on the values of peace, plurality and dialogue already contained within texts such as the Qur'an and Hadiths (teachings of the prophet) and Islamic history. While, ultimately, the success of peace education must be judged by its effects, the positive reception of this initiative represents a vital first step. According to the authors, the main factors contributing to acceptance were 
(a) an experienced Arabic-speaking external team, (b) a strong local partner, (c) a participatory methodology, and (d) the provision of in-kind aid for school improvement. The lessons learned from this intervention have potential to be applied to other education reform initiatives in the Muslim world.

Clearly, peace cannot be cultivated solely within separate communities; it is also necessary to promote dialogue and understanding between communities. It is one of the great ironies of our age that, despite the unprecedented communication between cultures that has accompanied globalisation, there remains immense distrust between religious communities. The authors of our second article in this issue, Sheila Gordon and Benjamin Arenstein, suggest that, to examine the state of interfaith relations, we should look to the domain where those relations are most fundamental and intimate; interfaith marriages. Their article, entitled "Interfaith education: A new model for today's interfaith families", begins with a discussion of the growing prevalence of interfaith marriages, especially in the United States, where some 40 per cent of households now include two different religious traditions. Marriage between people of different religions is not a new phenomenon, and exists in almost every part of the world. However, in most places, the assumption has been that the spouses could each retain their own faith, but would have to agree on just one for their children. Thus, religious communities tended to approve of (or at least condone) interfaith marriages, but not interfaith families.

The authors present in detail a model of religious education developed by the Interfaith Community (IFC), an independent non-profit organisation whose aim is to support respectful and non-didactic education in both traditions, thereby helping parents maintain a truly dual-faith household. While this model is particular to the United States and to families with Jewish and Christian heritages, its premises and structure have potential to be adapted to other religious combinations and other cultures and countries. The authors' findings indicate that, far from confusing or diluting a family's religious identity, engagement with a project like IFC enriches both parents' understandings of their tradition and makes the children more informed, tolerant and appreciative of religious difference.

For a long time, distance education (DE) was mostly regarded as a way to meet the educational needs of those unable, for whatever reason, to attend an institution of higher education. With recent developments in information and instructional technology, the scope and reach of DE have expanded greatly. As a result, it is no longer merely the "plan B" or "second-best option" for attaining a degree. In fact, its modularity, flexibility and economy (at a time when the costs of higher education have become prohibitive in many places), combined with profound changes in the labour market, mean there are more reasons than ever for freely choosing DE over the conventional attendance model. The early fanfare that surrounded the emergence of massive open online courses (MOOCs) and other Internet Age distance education offerings has dimmed somewhat; while The New York Times declared 2012 the "year of the MOOC" (Pappano 2012), five years later the predicted massive impact on higher education has not occurred. Just as Internet commerce has not replaced the bricks-and-mortar retail store, Internet-based distance education is no longer predicted to replace the university or adult education centre, but rather is expected to complement and augment them. 
Distance learning has entered a new era, one in which offerings are more closely tailored to the needs of learners and in which learners enjoy greater choice and autonomy in how, where and when they learn. To design successful DE courses it is therefore necessary to understand what motivates learners to choose this modality in the first place. This is the subject of our third article, entitled "Understanding Turkish students' preferences for distance education depending on financial circumstances: A large-scale CHAID analysis". Author Mehmet Firat applied a Chi squared Automatic Interaction Detector (CHAID) analysis to data collected from a sample of 18,856 students of the Open University of Turkey to investigate their reasons for choosing DE. His findings revealed that these students, 80 per cent of whom were in employment, chose DE primarily to support career advancement and to gain an accredited qualification. Geographical limitations, family considerations or economic difficulties (in terms of affording full-time tuition) were less relevant motivators. Perhaps the most significant implication of this study is that it reveals a great demand for a greater range of in-service training opportunities for workers, both in the private and public sectors.

Our fourth article is also concerned with choice and motivation. In "L'accès des filles à l'enseignement supérieur au Burkina Faso : choix parentaux, parcours d'étudiantes et défis" [Girls' access to higher education in Burkina Faso: parental choices, student trajectories, challenges], author Joséphine Wouango focuses on one of the most educationally disadvantaged groups in the world; African women of low socioeconomic status. While many countries in sub-Saharan Africa have made impressive strides in expanding access to education for girls, this success has mostly been seen in the primary and secondary sectors. Participation in tertiary education remains, in most of the region, low and inequitable (Pillay 2009). Yet, the author found that in Burkina Faso, at the University of Ouagadougou, the representation of young women from poorer families is relatively high. She therefore set out to examine what motivates less well-off parents to invest in extended schooling for their daughters, and what motivates the girls from these families to stay in the school system up to university level.

Based on a qualitative survey of students and their parents, this article highlights the social rationale determining the specific educational trajectories of these young women. The level of schooling of the older siblings, the girl's position in relation to her siblings, or concern for equity are some of the factors influencing parents' decisions to enrol their daughters in school. Parents also frequently invoke the argument that their daughters faithfully help them in return. As for the students, one of the most common motivations to persist with schooling and university studies, often in difficult circumstances, was the desire to help their parents. The article also highlights the importance of family support as a factor in girls attending school and university.

What can a society with a comprehensive formal education system and high rates of enrolment do to promote lifelong learning and the development of a learning society? This question has concerned education policymakers in Europe for a generation. Answers have been sought in the expansion of vocational and professional education, in adult education, and in the provision of greater opportunities for non-formal and experiential learning. Our fifth article, by Lars 
Norqvist and Eva Leffler, entitled "Learning in non-formal education: Is it 'youthful' for youth in action?" concerns the latter approach. The authors look at the European Voluntary Service (EVS), part of the Youth in Action (YiA) programme of the European Union (EU). EVS provides funding and support for organisations working in fields such as youth, sports, children, cultural heritage, culture, arts, animal welfare, environment and development cooperation to recruit volunteers between the ages of 17 and 30 for their projects. At the end of their time in EVS, volunteers receive a Youthpass which certifies and describes their participation.

For this study, data were collected through individual and focus group interviews with EVS volunteers, organisational decision-makers and trainers. The aim of the study was fivefold: (1) to understand why youth choose to participate in a nonformal learning programme; (2) to understand the mechanisms of learning in EVS; (3) to understand more generally the nature of non-formal learning and its differentiation from formal learning and education; (4) to evaluate Youthpass as a way to document and recognise non-formal learning; and (5) to understand how the young volunteers document and recognise their own learning. The findings offer several interpretations of non-formal learning, and reveal the difficulty of dividing learning into formal and non-formal categories. Instead, the authors argue for an integration of formal and non-formal educational contexts. The attempt to create discrete categories of formal and non-formal (and even informal) learning works against the development of flexible and interconnected learning opportunities that are stimulating, challenging and useful (what the authors summarise as "youthful"). To smooth the transition from systems of education to systems of lifelong learning and ultimately to the learning society, the borders between formal and non-formal learning must be removed, or at very least made more porous.

A recent issue of The Economist devoted a special report to the topic of lifelong learning, arguing "If 21 st-century economies are not to create a massive underclass, policymakers urgently need to work out how to help all their citizens learn while they earn" (The Economist 2017). Whereas organisations such as the EU, UNESCO, the OECD and the World Bank have long argued that lifelong learning is a prerequisite for the development of sustainable societies, it is rare to hear such an urgent plea from exponents of the economic "bottom line". Not long ago, the consensus among economists and business leaders was that vocational education, rather than lifelong learning, would yield the greater return on investment (ibid.). That view is now being challenged, not least by the final article in this issue.

Jeroen Lavrijsen and Ides Nicaise, in "Returns on vocational education over the life cycle: Between immediate labour market preparation and lifelong employability", contend that vocational education, while providing school leavers with skills of immediate value in the workplace, yields a diminishing return over time, as those skills lose relevance and the labour market changes. General education, by contrast, produces more flexible employees, equipped with foundational skills that facilitate lifelong participation in training and reskilling. The authors examine this trade-off between short-term gains and long-term losses by considering differences in the labour market careers of vocationally and generally educated respondents in the OECD's 2012 Programme for the International Assessment of Adult Competencies 
(PIAAC) study. Their results indeed suggest that the early benefits of vocational specialisation decrease over time; the authors relate this to its lower ability to equip secondary school students - future employees - with skills for lifelong learning.

As this is this year's first general issue of the International Review of Education Journal of Lifelong Learning (IRE), I would like to acknowledge the vital support provided entirely as a service of honour by our peer reviewers. I extend my gratitude and appreciation to the following individuals who reviewed articles for general and special issues in 2016:

Helen Abadzi, University of Texas at Arlington, United States of America

Christel Adick, Ruhr University Bochum, Germany

Abdel Rahamane Baba-Moussa, University of Abomey-Calavi, Benin

Zehlia Babaci-Wilhite, University of California, United States of America

Herman Baert, KU Leuven, Belgium

Zvi Bekerman, Hebrew University, Israel

Paul Bélanger, Université du Québec à Montréal, Canada

Stephanie Bengtsson, Wittgenstein Centre for Demography and Global Human Capital, Austria

Michal Bilewicz, University of Warsaw, Poland

Sandra Bohlinger, Technical University of Dresden, Germany

Mark Bray, University of Hong Kong, China

Martin Brueckner, Murdoch University, Australia

Mette Buchardt, Aalborg University, Denmark

Françoise Caillods, International Science Council, France

Michel Candelier, Université du Maine, France

John Chi-kin Lee, Education University of Hong Kong, China

Louay Constant, RAND Corporation, United States of America

Martial Dembélé, University of Montreal, Canada

Fred Dervin, University of Helsinki, Finland

XiaoJiong Ding, Shanghai Normal University, China

Nadia Edmond, University of Brighton, United Kingdom

Maren Elfert, University of British Columbia, Canada

César Guadalupe, Universidad del Pacífico, Peru

Alexandre Guilherme, Liverpool Hope University, United Kingdom

Zehavit Gross, Bar Ilan University, Israel

Günter Hefler, 3 s research laboratory, Vienna, Austria

Jeannine Hill Fletcher, Fordham University, United States of America

John Holford, University of Nottingham, United Kingdom

Wim Hoppers, Leiden University, The Netherlands

Muir Houston, University of Glasgow, United Kingdom

Timothy Denis Ireland, Federal University of Paraíba, Brazil

Tim Jensen, Syddansk University, Denmark

Ulla Højmark Jensen, Aalborg University, Denmark

Tavis D. Jules, Loyola University Chicago, United States of America

Everard van Kemenade, Fontys University of Applied Sciences, The Netherlands 
Leslie Limage, Paris, France

Jyri Manninen, University of Eastern Finland

Aïcha Maherzi, University of Toulouse II, France

Peter Mayo, University of Malta, Msida, Malta

Veronica McKay, University of South Africa

Michael McVey, Eastern Michigan University, United States of America

Tamar Meisels, Tel Aviv University, Israel

Abiy Menkir Gizaw, Bahir Dar University, Ethiopia

Nagwa Megahed, American University in Cairo, Egypt

Heidi Morrison, University of Wisconsin, United States of America

Marta Moskal, University of Glasgow, United Kingdom

Norbert Nikièma, University of Ouagadougou, Burkina Faso

Bridget O'Connor, New York University, United States of America

Marie Odile Paulet, Toulouse, France

Henning Olesen, Roskilde University, Denmark

Margarita Pavlova, Education University of Hong Kong, China

David Post, Pennsylvania State University, United States of America

Esther Prins, Pennsylvania State University, United States of America

Judith Purkarthofer, University of Oslo, Norway

Alan Rogers, University of East Anglia, United Kingdom

Daniel Schugurensky, Arizona State University, United States of America

Conor Snoek, University of Alberta, Canada

Robert Strathdee, RMIT University, Australia

Darko Šrajn, Educational Research Institute, Slovenia

Nelly Stromquist, University of Maryland, United States of America

Karla Suomala, Luther College, United States of America

Elinami Swai, Open University of Tanzania

Nisha Thapliya, University of Newcastle, United Kingdom

Leon Tikly, University of Bristol, United Kingdom

Sue Timmis, University of Bristol, United Kingdom

Carlos Vargas, UNESCO, France

Eva Vetter, University of Vienna, Austria

Pirjo Kristiina Virtanen, University of Helsinki, Finland

Joseph Zajda, Australian Catholic University, Melbourne, Australia

\section{References}

Hickel, J. (2016). Global inequality may be much worse than we think. The Guardian, 8 April. Retrieved

20 March 2017 from https://www.theguardian.com/global-development-professionals-network/ 2016/apr/08/global-inequality-may-be-much-worse-than-we-think.

Lakner, C., \& Milanovic, B. (2013). Global income distribution from the fall of the Berlin wall to the great recession. Policy Research Working Paper 6719. Washington, DC: World Bank.

Pappano, L. (2012). The year of the MOOC. The New York Times, 2 November. Retrieved 22 March 2017 from http://www.nytimes.com/2012/11/04/education/edlife/massive-open-online-courses-aremultiplying-at-a-rapid-pace.html. 
Pillay, P. (2009). Challenges and lessons from East and Southern Africa. In J. Knight (Ed.), Financing access and equity in higher education (pp. 19-39). Rotterdam: Sense.

Samoff, J., Dembélé, \& Sebatane, E.M. (2013). Scaling up by focusing down. Creating space and capacity to extend education reform in Africa. In L. Tikly \& A.M. Barrett (Eds.), Education quality and social justice in the global south: Challenges for policy, practice and research (pp. 121-138). Abingdon: Routledge.

Tanzi, V., \& Schuknecht, L. (2000). Public spending in the 20th century: A global perspective. Cambridge: Cambridge University Press.

The Economist (2017). Equipping people to stay ahead of technological change. The Economist, 14 January. Retrieved 20 March 2017 from http://www.economist.com/news/leaders/21714341-it-easysay-people-need-keep-learning-throughout-their-careers-practicalities. 